\title{
Queen Longevity and Fecundity Affect Conflict with Workers over Resource Inheritance in a Social Insect
}

\author{
Edward J. Almond, ${ }^{1}$ Timothy J. Huggins, ${ }^{1}$ Liam P. Crowther, ${ }^{1}$ Joel D. Parker,${ }^{2, \star}$ \\ and Andrew F. G. Bourke ${ }^{1, \dagger}$
}

1. School of Biological Sciences, University of East Anglia, Norwich Research Park, Norwich, Norfolk NR4 7TJ, United Kingdom; 2. School of Biological Sciences, University of Southampton, Life Sciences Building, Highfield Campus, Southampton SO17 1BJ, United Kingdom

Submitted June 27, 2018; Accepted September 21, 2018; Electronically published December 26, 2018

Online enhancements: appendixes, supplemental material. Dryad data: https://dx.doi.org/10.5061/dryad.84033r7.

\begin{abstract}
Resource inheritance is a major source of conflict in animal societies. However, the assumptions and predictions of models of conflict over resource inheritance have not been systematically tested within a single system. We developed an inclusive fitness model for annual eusocial Hymenoptera that predicts a zone of conflict in which future reproductive workers are selected to enforce nest inheritance before the queen is selected to cede the nest. We experimentally tested key elements of this model in the bumblebee Bombus terrestris. In colonies from which queens were sequentially removed, queen tenure was significantly negatively associated with worker male production, confirming that workers gain direct fitness by usurping the queen. In unmanipulated colonies, queen fecundity decreased significantly over the latter part of the colony cycle, confirming that workers' indirect fitness from maintaining queens declines over time. Finally, in an experiment simulating loss of queen fecundity by removal of queens' eggs, worker-toqueen aggression increased significantly and aggressive workers were significantly more likely to become egg layers, consistent with workers monitoring queen fecundity to assess the net benefit of future reproduction. Overall, by upholding key assumptions and predictions of the model, our results provide novel empirical support for kin-selected conflict over resource inheritance.
\end{abstract}

Keywords: bumblebee, kin selection, resource inheritance, social insect, worker reproduction.

\section{Introduction}

Resource inheritance is widespread within animal societies and occurs in various forms in different taxa (Myles 1988; Ragsdale 1999; Hart and Monnin 2006). These forms in-

\footnotetext{
* Present address: Department of Biological Sciences, State University of New York at Plattsburgh, Plattsburgh, New York 12901.

† Corresponding author; email: a.bourke@uea.ac.uk.

ORCIDs: Parker, http://orcid.org/0000-0002-1217-0723; Bourke, http://orcid .org/0000-0001-5891-8816.

Am. Nat. 2019. Vol. 193, pp. 256-266. (C) 2018 by The University of Chicago. 0003-0147/2019/19302-58575\$15.00. All rights reserved. This work is licensed under a Creative Commons Attribution 4.0 International License (CC BY 4.0), which permits reuse of the work with attribution.

DOI: $10.1086 / 701299$
}

clude nest, den, and territory inheritance in social birds and mammals (Myles 1988; Alexander et al. 1991; Emlen 1995; Hart and Monnin 2006; Kingma 2017) and nest inheritance by replacement queens (Myles 1988; Hart and Monnin 2006; Bang and Gadagkar 2012; Hoffmann et al. 2012) or reproductive workers (Franks et al. 1990; Bourke 1994; Heinze et al. 1997; Friend and Bourke 2014) in eusocial insects (ants, bees, wasps, and termites). Inheritance typically involves not just the physical structure of a nest, den, or territory but also the resources within it, including a labor force of helpers or workers (Myles 1988; Emlen 1995; Hart and Monnin 2006). Although the various systems of resource inheritance differ in their details, they share fundamental similarities. These are that $(a)$ offspring inherit from parents a resource required for breeding and $(b)$ potential kin-selected conflict arises over the optimal time for inheritance because the parties have different relative relatednesses to one another's offspring (Alexander et al. 1991; Emlen 1995; Hart and Monnin 2006; Bourke 2007). The occurrence of such conflict predicts that offspring should monitor changes in the net inclusive fitness benefit of keeping parents alive and take over the resource when fitness from future offspring reproduction exceeds fitness from future parental reproduction (Alexander et al. 1991; Bourke 1994; Emlen 1995). In addition, because (all else equal) both parties benefit from parental reproduction when parental fecundity is high, parents should signal their fecundity to offspring and offspring should respond facultatively to changes in parental fecundity to time their attempts to take over the resource (Alexander et al. 1991; Emlen 1995).

The eusocial Hymenoptera (ants, bees, and wasps) include numerous examples of societies with potential conflict over nest inheritance between queens and workers. In many species, helper females (workers) that are nonreproductive in the presence of the queen inherit the nest from her and then produce haploid male offspring from unfertilized eggs (Bourke 1994; Liebig et al. 2005; Monnin et al. 2009; Leadbeater et al. 2011). Studies suggest that queens signal their fecundity to workers via chemicals borne on 
their body surfaces, eggs, or both, in the presence of which workers downregulate their own reproduction (Liebig et al. 2005; Peeters and Liebig 2009; Holman et al. 2010; Holman 2014, 2018; Van Oystaeyen et al. 2014; Smith and Liebig 2017). Queens may also actively prevent worker reproduction in their presence by eating workers' eggs (Wenseleers and Ratnieks 2006). In addition, workers in some annual species harass their queen toward the end of the colony cycle and may eventually kill her (worker matricide), following which they lay male eggs; this suggests that workers can enforce nest inheritance in order to reproduce (Trivers and Hare 1976; Ratnieks 1988; Bourke 1994; Strassmann et al. 2003). Confirming this prediction, workers in the wasp Dolichovespula arenaria were found to kill their mother queen preferentially in colonies headed by a singly mated queen, that is, colonies in which workers stood to gain greatest fitness (Loope 2015).

To investigate potential conflict over resource inheritance more fully, we constructed an inclusive fitness model of queen-worker conflict over nest inheritance in eusocial Hymenoptera (fig. 1; app. A; apps. A-D are available online). The model is based on the concept of parent-offspring conflict over resource inheritance (Alexander et al. 1991; Emlen 1995; Hart and Monnin 2006) and, in detail, on models of Bourke $(1994,2007)$. It assumes that workers gain direct fitness from nest takeover via expelling or killing the queen (because this permits workers to lay male eggs unhindered by the queen) but that this incurs a loss of indirect fitness from workers not rearing any queen-produced sexuals (workers' siblings) after nest takeover. The model also assumes that workers can monitor queen fecundity and predicts that if queen fecundity decreases over time, the workers' cost-tobenefit ratio for nest takeover may fall to a threshold value below which workers are selected to expel or kill the queen and commence egg laying (fig. 1; app. A). The model therefore predicts that workers' tolerance of queens and reproductive restraint are functions of queen fecundity and that workers that go on to lay eggs should be the first to respond behaviorally (e.g., with aggression) to declines in queen fecundity, given that laying workers reach their critical threshold for nest takeover before the other parties (fig. 1).

The detailed assumptions and predictions of this and similar models of conflict over resource inheritance have not been systematically studied in any single resource inheritance system. To meet this requirement, we investigated conflict over nest inheritance in the eusocial buff-tailed bumblebee (Bombus terrestris). Bombus terrestris colonies are headed by one singly mated queen and follow an annual cycle in which queens found new colonies in spring and only young newly mated queens of the year survive to overwinter at the season's end (Duchateau and Velthuis 1988). Workers cannot mate but can produce haploid male offspring from unfertilized eggs; once worker egg laying has started, $28 \%-45 \%$ of workers



Figure 1: Inclusive fitness model of queen-worker conflict over nest inheritance in an annual eusocial Hymenopteran with worker reproduction in queenless conditions. $c / b$ is the cost-to-benefit ratio below which any party favors queen death and nest inheritance, where $c$ is the number of queen-produced sexuals that would have been reared between the time of the queen's death and season's end had the queen lived and $b$ is the number of worker-derived males that could be reared between the queen's death and season's end. $T_{\mathrm{LW}}, T_{\mathrm{NLW}}$, and $T_{\mathrm{Q}}$ are critical threshold values of $c / b$ for laying workers (LW), nonlaying workers (NLW), and the queen (Q), respectively. Zones are as follows: (i) $c / b>1.0$, no inheritance (all parties favor the queen retaining the nest and her reproductive monopoly); (ii) $1.0>c / b>0.5$, conflict over inheritance (workers [LW and NLW] but not the queen favor nest inheritance); and (iii) $c / b<0.5$, no conflict (all parties, including the queen, favor nest inheritance). The model assumes that workers rear both sexes of queen-produced sexuals and hence that workers' relatedness to queen-produced sexuals (averaged across both sexes) is 0.5. If queens produce only males, the model's qualitative predictions remain the same. See appendix A for further details.

lay eggs, laying approximately $70 \%$ of all male eggs and overall accounting for $5 \%-10 \%$ of adult male production (Bloch 1999; Bloch and Hefetz 1999b; Alaux et al. 2004b; LopezVaamonde et al. 2004; Zanette et al. 2012). Colonies typically pass three critical points during the colony cycle, which subdivide the colony cycle into definable though not entirely discrete phases (Duchateau and Velthuis 1988; Bourke and Ratnieks 2001; Duchateau et al. 2004; Lopez-Vaamonde et al. 2009). The first critical point, the "switch point," occurs when the queen changes from laying diploid female eggs yielding workers or new queens to laying mainly or entirely haploid eggs yielding males (Duchateau and Velthuis 1988; Holland et al. 2013). The second, the "competition point," occurs when workers begin to lay their own male eggs and exhibit aggression toward the queen and one another (Duchateau and Velthuis 1988; Duchateau 1989; Bloch 1999). The third occurs when the queen dies and the colony enters the queenless phase, during which most worker-derived males are produced (Alaux et al. 2004b; Lopez-Vaamonde et al. 2004; Zanette et al. 2012). While alive, queens police worker 
male production by eating approximately $50 \%$ of worker-laid eggs (Duchateau 1989; Zanette et al. 2012), suggesting a direct fitness benefit to workers of expelling or killing the queen. Queen death may arise from intrinsic causes or be caused by worker matricide (Bourke 1994; Lopez-Vaamonde et al. 2009). Moreover, queen longevity is positively correlated with the number of adult sexuals (new queens and males) produced by queens and negatively correlated with workers' reproductive success - that is, the proportion of adult males produced by workers (Lopez-Vaamonde et al. 2009) — suggesting the existence of indirect fitness costs and direct fitness benefits to workers of queen death, as our conflict model assumes (fig. 1).

We performed three separate experiments. In experiment A, we tested the assumption of the model that following the switch point, $B$. terrestris workers gain direct fitness by expelling or killing the queen. To do this, we tested whether the observed negative correlation of queen longevity and workers' reproductive success (Lopez-Vaamonde et al. 2009) is purely correlational or has a causal basis (causation hypothesis), that is, whether early queen death causes greater queenless worker male production. It might seem self-evident that this would be the case, because early queen death leads to a longer queenless phase. But an alternative hypothesis is that queen and worker quality (here including longevity and fecundity) covary. Specifically, long-lived queens might have low-quality, weakly reproductive workers, and short-lived queens might have high-quality, strongly reproductive workers (covariance hypothesis). Such a negative covariance of queen and worker quality (cf. the positive genetic covariance of queen and worker fecundity described in ants by Holman et al. [2013b]) could be genetic or phenotypic in origin and could arise from multiple causes. The causation and covariance hypotheses both predict a negative correlation of queen longevity and workers' reproductive success, but they also predict different outcomes of manipulating queen longevity by removing queens. The causation hypothesis predicts that workers in all colonies from which queens are removed early should produce worker-derived males and that, all else equal, the amount of queenless worker male production should increase with the length of the queenless phase. The covariance hypothesis predicts that workers in some colonies from which queens are removed early should produce few or no males, since, according to the hypothesis, workers under some queens would be low-quality, weakly reproductive workers.

In experiment $\mathrm{B}$, we tested the assumption of our model that, in B. terrestris, queen fecundity (rate of egg production) decreases with time in the latter half of the colony cycle. Finally, in experiment $C$ we tested the assumption of the model that $B$. terrestris workers monitor queen fecundity and the predictions of the model that workers respond in a reproductively self-interested manner to a perceived decline in queen fecundity and that future reproductive workers lead this response. Worker monitoring of queen fecundity predicts that experimentally simulating a decrease in queen fecundity (by removal of the queen's eggs) should induce workers to behave aggressively to queens and/or advance the start of egg laying (competition point). A previous experiment in polistine wasps suggested that when eggs of the queen were removed, workers increased their egg laying although not their aggression (Liebig et al.2005), consistent with monitoring of queen fecundity. Following the competition point, $B$. terrestris workers are aggressive toward queens (Duchateau and Velthuis 1988; Duchateau 1989; Bloch 1999). In experiment C, we therefore predicted that workers first behaving aggressively toward queens should, on average, be the workers that go on to lay eggs. Overall, by conducting tests of relevant assumptions and predictions within a single system, we provide novel empirical support for the widely applicable concept of kinselected within-group conflict over resource inheritance.

\section{Methods}

Experiment A: Experiment to Determine the Effect of Queen Longevity on Workers' Reproductive Success

We determined the effect of queen longevity on workers' reproductive success by removing the queen from sets of colonies at differing intervals following the switch point (date of first queen-laid male egg), simulating queen death, and then recording the amount of male production by workers in the resulting queenless colonies. We obtained 58 colonies of Bombus terrestris from a commercial supplier in two cohorts and maintained them under standard conditions (see app. B). All colonies were monitored daily and kept until no male eclosion (emergence of adult from pupa) had occurred for 7 days and there were no mature larvae or pupae, with fewer than 10 workers remaining alive (Lockett et al. 2016). Daily monitoring included counting all newly eclosed workers and sexuals (males and gynes or young queens) and removing any sexuals on the day of their eclosion. In this and the following experiments, we recorded behavior under red light by direct observation or by filming colonies using digital camcorders (Sony DCR-SR32).

We randomly assigned colonies from the cohorts to experimental groups defined by the number of days after the switch point at which queens were removed (i.e., group 1: mean of 20 days, $n=17$ colonies; group 2: mean of 33 days, $n=8$ colonies; group 3: mean of 54 days, $n=9$ colonies; table B1, available online). In a control group, queens were not removed but died naturally ( $n=24$ colonies; table B1). Full details of assignments of colonies to groups are given in appendix B. Because $B$. terrestris workers produce only a small percentage $(\sim 2 \%)$ of males in queenright (with a queen) colonies (Lopez-Vaamonde et al. 2004), we assumed that males eclosing up to 26 days (males' egg-to-adult developmental time) after the date of the queen's death or removal 
were queen produced and that males eclosing after this date were worker produced (Lopez-Vaamonde et al. 2009).

\section{Experiment B: Experiment to Determine Queen Fecundity as a Function of Time}

Bombus terrestris queens lay eggs into waxen cells, and there can be several eggs laid per cell (Alford 1975; Bloch and Hefetz 1999b). The rate of queen egg laying therefore has two components - the frequency of queen egg-laying events (each event being one bout of laying into an egg cell), and the number of eggs laid per event (cell). We measured changes in each of these components with time.

Frequency of Queen Egg-Laying Events. To measure this component, we used the original 10 control colonies from cohort 1 in experiment A. We digitally filmed each colony under red light for 3-4 h at weekly intervals (Zanette et al. 2012), starting at 11:00-14:00 on each day, until the natural death of the queen. Filming began a mean \pm SD of $11.8 \pm 7.3$ days after the actual switch point and continued for $50.1 \pm 18.8$ days. We then viewed all film ( $231 \mathrm{~h}$ in total) and scored all instances of the queen laying eggs into a cell. Time was measured with respect to the switch point because in these colonies the timing of the competition point was not determined. Because the assay continued for a mean of 62 days following the switch point and the competition point typically occurs $\sim 2$ weeks after the switch point (Duchateau and Velthuis 1988; Zanette et al. 2012), the period of the assay encompassed the post-competition-point phase of the focal colonies.

Number of Eggs Laid per Egg-Laying Event. We measured this component of queen fecundity using five colonies from an additional cohort, cohort 3 (see app. C). To be certain that eggs counted within cells were all queen laid, we periodically isolated queens in a mesh cage within their colonies and allowed them to lay eggs within them. In brief (see app. C for details), queens were caged in situ within the nest for 2 days out of every 7 , retaining contact with workers, brood, and wax throughout. Queens constructed egg cells in the cages, and we counted the eggs inside all such cells (mean of 0.48 cells per $48 \mathrm{~h}$ ). This process was continued until each queen's death (i.e., until a mean \pm SD of $25 \pm 6$ days following the switch point) and so is again likely to have encompassed the post-competition-point phase of the focal colonies.

\section{Experiment C: Experiment to Determine the Effect of Queen Fecundity on Worker-to-Queen Aggression}

We obtained 24 incipient $B$. terrestris colonies from a commercial supplier (see app. D) and maintained them as in experiment A. All newly eclosed workers were marked with plastic individually numbered discs daily throughout the experiment. On reaching a size of 15 workers, colonies were grouped into pairs based on having similar amounts of brood. Within each pair, the two colonies were randomly assigned to either the treatment category or the control category. The treatment involved the experimental removal of all of the queen's eggs, whereas the control (for disturbance) involved the removal and replacement of all of the queen's eggs. In both cases, from the point when colonies reached a size of 20 workers (just before the estimated time of the switch point; see experiment A), we carefully removed all new egg cells from the colony on the day each egg cell appeared. We opened the egg cells and counted and removed the eggs, using fresh sterile toothpicks to avoid any transfer of external contaminants. For treatment colonies, the eggs were stored at $-20^{\circ} \mathrm{C}$ for subsequent genetic analysis. For control colonies, we placed the eggs back in the egg cell, sealed it, and inserted it into its original position in the colony. We stopped all egg cell manipulations in each colony when it reached its competition point; this was to ensure that all removed eggs were queen-laid eggs.

After egg cell manipulations had begun, we carried out six 1-min observation bouts for each colony per day to monitor colonies for worker egg laying (and so determine the date of the competition point and the identity of egg-laying workers) and to record the identities of all workers showing aggressive behaviors toward the queen and the type of aggression exhibited. Aggressive behaviors were classified as noncontact behavior (wing buzzing next to the queen) or contact behavior (biting, grappling, and pushing the queen) based on Duchateau (1989). We also filmed all colonies for $50 \mathrm{~min}$ each per day (between 09:00 and 14:00) for the remainder of the experiment. The experiment was ended 18 days after the detection of the competition point. The date of the switch point was determined by sexing of eggs using microsatellite genotyping or by back calculation from the timing of male production (see app. D).

For measuring worker-to-queen aggression rates, we viewed the 50 -min films for each colony from time points 2 days after the start of manipulations, 6 days prior to the competition point, and at 2-day intervals from this point until up to 18 days after the competition point. The numbers of aggressive acts directed by workers at the queen were scored blindly with respect to treatment (see app. D). We then divided these by the total time the queen was visible on screen, to give the mean aggression rate. Since occurrences of wing buzzing represented the majority of aggressive actions performed toward the queens (369/436 actions), they were analyzed separately. Levels of queen activity were also estimated from the films to control for possible effects of queen activity (Nonacs et al. 2004) on worker-to-queen aggression (see app. D). Following the end of the experiment, the degree of workers' ovarian activation was measured by ovarian dissection (see app. D). 


\section{Statistical Methods}

Data were analyzed using $\mathrm{R}$ version 2.14.1 ( $\mathrm{R}$ Development Core Team 2011) with linear mixed models (LMMs) or generalized linear mixed models (GLMMs) fitted using package lme4 (Bates et al. 2011). For all models, we initially fitted a maximal model that included all specified fixed terms and their interactions. Minimal adequate models were selected from the maximal model with the dredge function in the package MuMIn (Barton 2018), which searches all possible predictor combinations and selects models by comparing values of the second-order Akaike information criterion (AICc; Pinheiro and Bates 2002). The candidate model with the lowest AICc was reported as the best model. Models in which the response variable was count data were tested for overdispersion by comparing the Pearson residual sum of squares to the residual degrees of freedom using a $\chi^{2}$ test.

In experiment $\mathrm{A}$, to determine the effect of queen longevity (time before queen removal or death, dated from the switch point; more generally, queen tenure) on queen reproductive success (total queen sexual offspring produced, or queen sexual production) and worker reproductive success (measured as either the proportion of total males produced by workers or the per-worker proportion of worker-produced males), a LMM was fitted. In each model, queen removal group was fitted as a random factor and queen longevity, cohort, treatment (whether the queen was removed or died naturally), and the mean rate of worker production were fitted as fixed effects.

In experiment B, two separate models were produced. For the measurements of frequency of queen egg-laying events, a binomial GLMM was fitted with occurrence of queen egglaying events (coded as a binary variable) as the dependent variable, queen identity as a random effect, and time (relative to the switch point) and whether males had started to eclose (coded as a binary factor) as fixed effects. For the measurements of number of eggs laid per event, a Poisson GLMM was fitted with the number of eggs laid in $48 \mathrm{~h}$ as the dependent variable, queen identity as a random effect, and time (days after the switch point), the number of egg cells built by queens, and their interaction as fixed effects.

In experiment $\mathrm{C}$, the rate of worker-to-queen aggression as a function of treatment was analyzed with a LMM, with treatment, time relative to the competition point (divided into three periods), and the number of workers present at the time of measurement modeled as fixed effects and nest identity (nested within pairs) and day of observation modeled as random effects. In these analyses, noncontact (wing buzzing) and contact (biting, grappling, and pushing) worker behaviors were treated separately. The three time periods were as follows: start (i.e., at the start of the egg-manipulation period; mean $\pm \mathrm{SD}$ of $19 \pm 5$ days before the competition point), pre-CP (i.e., near the end of the egg-manipulation pe- riod; $2 \pm 2$ days before the competition point), and post-CP (i.e., following the egg-manipulation period; $8 \pm 4$ days after the competition point). The first two time periods were defined so as to allow for the possibility that the treatment required time to have an effect. Post hoc Tukey comparisons were then carried out on this model. To investigate whether queen activity differed between treatment and control groups during the egg-manipulation period, two separate LMMs, containing as the dependent variable either the distance traveled per minute by the queen or the number of workers she encountered per minute, were fitted with treatment as a fixed effect and nest identity (nested within pairs) and day of observation as random effects. Worker-to-queen aggression as a function of worker reproductive status was examined by fitting separate binomial GLMMs for workers exhibiting aggressive behavior during either the egg-manipulation period or the postmanipulation period and for workers exhibiting aggressive behavior during the egg-manipulation period only. The proportion of workers with active ovaries, or the proportion of workers that had been observed to lay eggs, was fitted as the dependent variable, with treatment and worker aggression status (aggressive or not aggressive toward queen) fitted as independent variables. Finally, to analyze queen egglaying rates, a Poisson GLMM was fitted with treatment and time relative to the competition point as fixed effects and nest identity, nested within pairs, and day of observation as random effects. The response variable was mean queen number of eggs laid per day, which was measured by counting, during the experimental removals of eggs, all eggs within each egg cell produced by the queen every $24 \mathrm{~h}$. All means are reported \pm 1 SD. Data are deposited in the Dryad Digital Repository (Almond et al. 2018; https://dx.doi.org/10.5061 /dryad.84033r7).

\section{Results}

Experiment A: Experiment to Determine the Effect of Queen Longevity on Workers' Reproductive Success

There was a significant positive relationship between queen longevity and queen sexual production (best LMM, $P<$ $.0001, n=58$ colonies; fig. S1, tables S1a, S1b; fig. S1, fig. S2, and tables $\mathrm{S} 1-\mathrm{S} 8$ are available online). There was no significant effect of cohort or treatment $(P=.77$ and $P=.56$, respectively; tables S1a, S1b). The latter result meant that colonies from which queens were experimentally removed and colonies in which queens died naturally showed similar relationships between queen longevity and queen sexual production.

There was a significant negative relationship between queen longevity and worker reproductive success measured both as the proportion of total males produced by workers (best LMM, $P<.0001, n=58$ colonies; fig. 2, tables S2a, $\mathrm{S} 2 \mathrm{~b})$ and as the per-worker proportion of worker-produced 


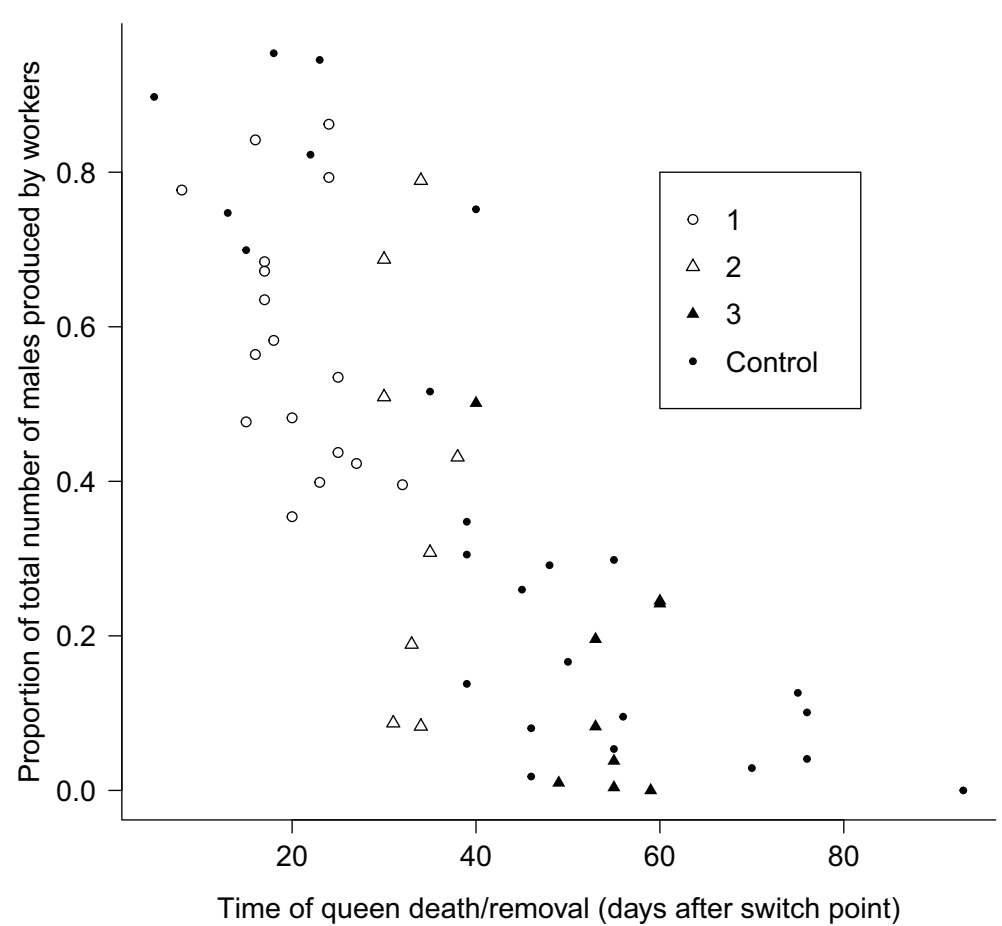

Figure 2: Worker reproductive success (proportion of total males produced by workers) in Bombus terrestris colonies as a function of queen longevity (experiment A). Queens were removed at a mean of 20,33, and 54 days after the switch point in groups $1(n=17$, white circles), $2(n=8$, white triangles), and 3 ( $n=9$, black triangles), respectively. In the control group ( $n=24$, black circles), the queen was allowed to die naturally.

males $(P<.0001$; tables S2c, S2d). There was no significant effect of cohort or treatment or their interaction on the proportion of total males produced by workers, but there was a significant effect of these on the per-worker proportion of worker-produced males (tables S2a-S2d). However, for both measures of worker reproductive success, queen longevity had the most consistent effect (tables S2a-S2d). No colony in group $1(n=17)$, from which queens were removed earliest, failed to produce worker-produced males (the minimum proportion of worker-produced males in any colony was 35\%; fig. 2). These findings support the causation hypothesis for an influence of queen longevity on the direct fitness of workers and fail to support the covariance hypothesis.

\section{Experiment B: Experiment to Determine Queen Fecundity as a Function of Time}

Frequency of queen egg-laying events. Queen egg laying showed a marginally nonsignificant decline in observed frequency after the switch point (best GLMM, $P=.051$, $n=64$ observations of 10 queens; fig. $3 a$; tables S3a, S3b).

Number of eggs laid per egg-laying event. The number of eggs laid per cell by queens decreased significantly as a function of time following the switch point (best GLMM,
$P=.0001, n=13$ observations from five queens; fig. $3 b$, tables S4a, S4b).

\section{Experiment C: Experiment to Determine the Effect of Queen Fecundity on Worker-to-Queen Aggression}

Competition point. There was no significant difference between paired treatment and control colonies in the mean date of the competition point, relative either to the switch point (treatment $=10 \pm 5$ days; control $=6.8 \pm 5.0$ days; paired $t$-test, $\mathrm{df}=11, t=1.15, P=.28$ ) or to the start of the egg-manipulation period (treatment $=22 \pm 4$ days; control $=24 \pm 7$ days; paired $t$-test, $\mathrm{df}=11, \mathrm{t}=1.01$, $P=.34)$. Therefore, workers did not modify the timing of the onset of egg laying in response to the experimental absence of queen-laid eggs.

Worker-to-queen aggression as a function of treatment. For noncontact behaviors (wing buzzing), there was a significant interaction between treatment and the period in which aggression occurred (best LMM, $P=.003$; tables S5a, S5b). Specifically, post hoc Tukey tests showed that the mean aggression rate was significantly higher in treatment colonies than in control colonies in the pre-CP period (i.e., at the end of the egg-manipulation period) but not at the 
a

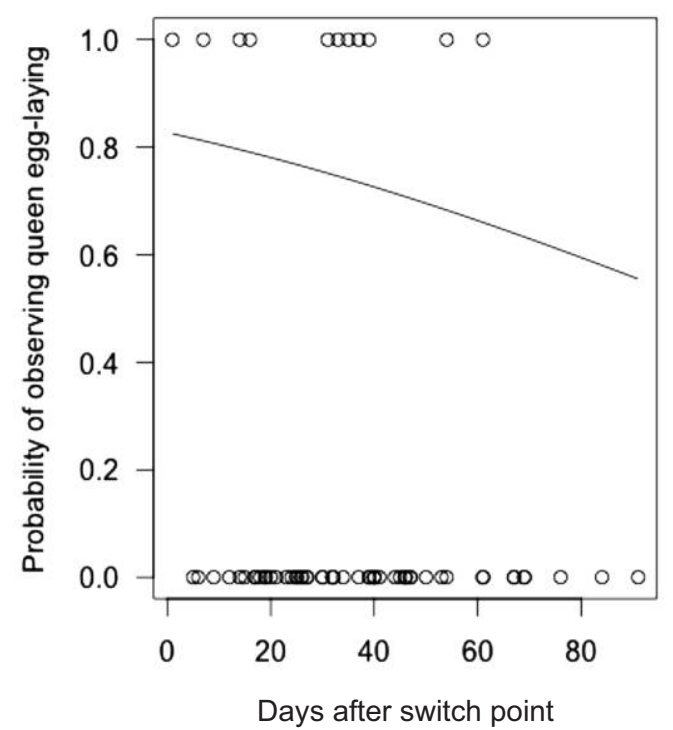

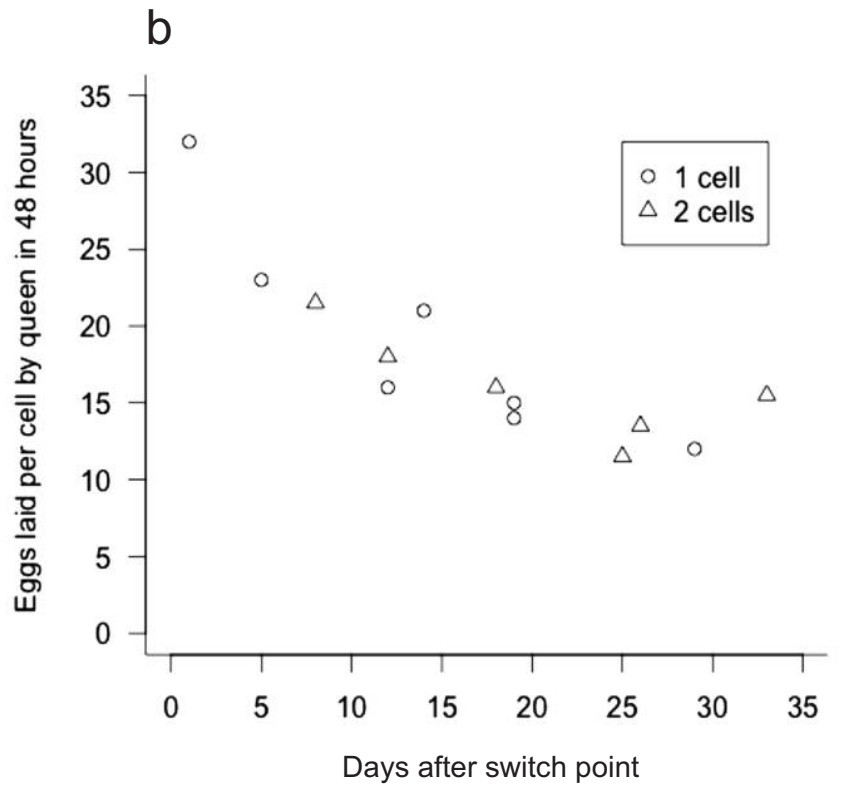

Figure 3: Change in Bombus terrestris queen fecundity with time since switch point (experiment B). a, Predicted probability (from a binomial generalized linear mixed model) of observing a queen egg-laying event following the switch point. $0=$ no egg laying observed; $1=$ egg laying observed. $n=64$ observations each of $3.6 \pm 0.7 \mathrm{~h}$, over 10 queens. $b$, Number of eggs per egg cell laid by queens following the switch point. Circles $=$ one egg cell constructed in $48 \mathrm{~h}$; triangles $=$ two egg cells constructed in 48 h. $n=5$ queens observed over 35 days.

start of the egg-manipulation period or in the post-CP period following it (difference between treatment and control aggression rates in the pre-CP period $=2.3$ wing buzzes received per hour [95\% CL $=0.65-3.98] ; P=.001 ;$ fig. 4 ). Therefore, removing queens' eggs caused the workers to act more aggressively (by wing buzzing) toward queens.

For contact behaviors, there were no significant effects of any fixed factors or interactions, and the best LMM contained only an intercept (best LMM that included treatment, delta $=3.92, P=.67$; tables S5c, S5d).

Worker-to-queen aggression as a function of worker reproductive status. Comparing aggressive and nonaggressive workers within each colony, we found that a significantly greater proportion (mean, $81 \% \pm 14 \%$ ) of workers that were aggressive toward their queen during any of the experimental periods were ovary activated compared with the proportion $(57 \% \pm 22 \%)$ of nonaggressive workers that were ovary activated (treatment and control colonies pooled, best GLMM, $P<.0001$; tables S6a, S7a, S7b). When considering only the aggression occurring during the period of egg manipulation, we again found that a significantly greater proportion $(85 \% \pm 15 \%)$ of workers that were aggressive toward the queen were ovary activated compared with the proportion $(64 \% \pm 22 \%)$ of nonaggressive workers that were ovary activated (best GLMM, $P<.0001$; tables S6b, S7c, S7d). Using data on workers identified through direct obser- vation to be egg layers in the post-egg-manipulation period, we also found that a significantly greater proportion of workers $(30 \% \pm 20 \%)$ that were aggressive toward the queen over any period were egg layers compared with the proportion of workers $(16 \% \pm 13 \%)$ that were not aggressive toward the queen over any period that were egg layers (best GLMM, $P=.0006$; tables S6c, S7e, S7f). Finally, considering only the aggression occurring during the period of egg manipulation, we found that a significantly greater proportion of workers $(32 \% \pm 23 \%)$ that were aggressive toward the queen were egg layers compared with the proportion of workers $(19 \% \pm 15 \%)$ that were not aggressive toward the queen that were egg layers (best GLMM, $P=.0006$; tables S6d, S7g, S7h). Therefore, there was an association between worker aggression toward the queen and workers' reproductive status, and, specifically, workers that were aggressive toward the queen during the egg-manipulation period were significantly more likely to have activated ovaries and to lay eggs. Treatment and control colonies were pooled in these analyses because the proportion of workers that were egg layers following the eggmanipulation period did not differ significantly between them (tables S7e-S7h).

Unexpectedly, we also found that queens in the treatment group increased the total number of eggs laid per day (assessed by counting the number of egg cells constructed and the number of eggs within egg cells) as the egg-manipulation period 


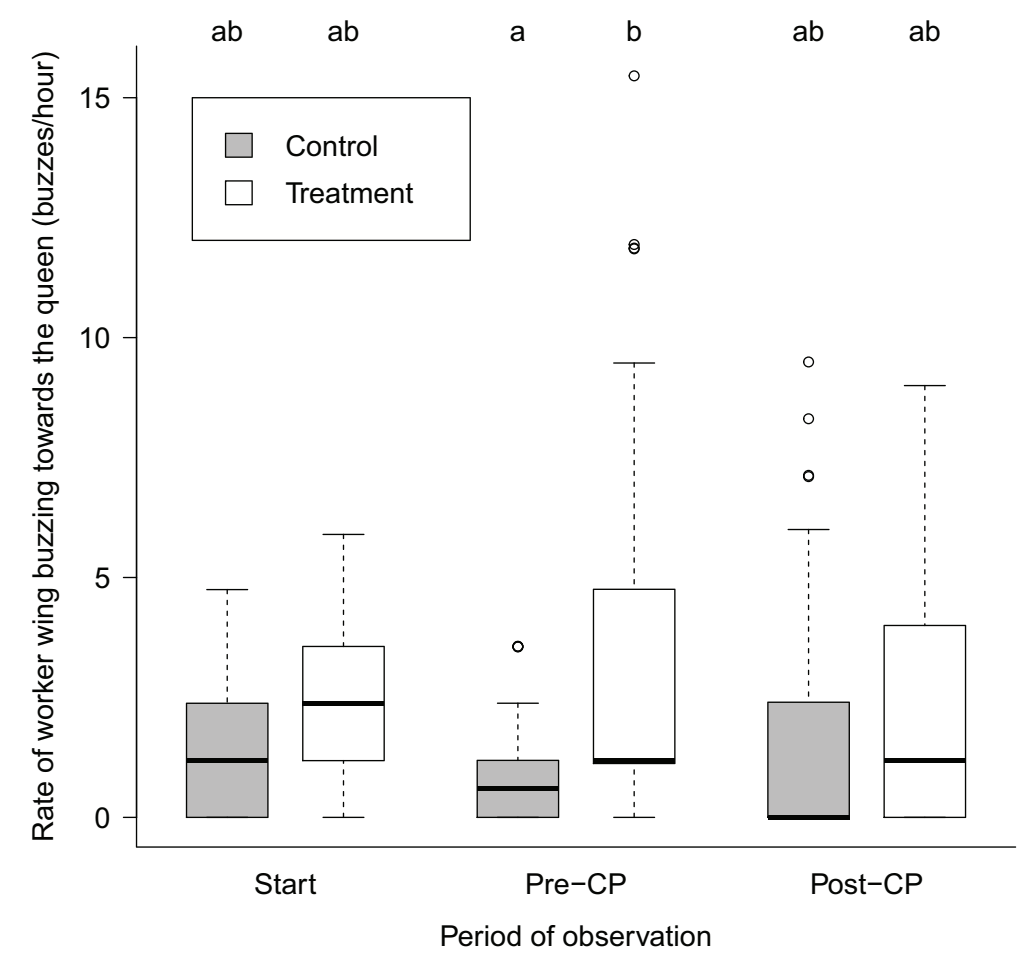

Figure 4: Mean rate of wing buzzing directed by Bombus terrestris workers toward the queen, per hour (experiment C). Treatment $=$ queens' eggs removed before competition point; control = queens' eggs removed and replaced. Period of observation: start = start of the egg-manipulation period; pre- $\mathrm{CP}=$ near the end of the egg-manipulation period, shortly before the competition point; post- $\mathrm{CP}=$ following the egg-manipulation period, after the competition point (see text for details). Bold bars indicate medians, boxes indicate quartiles, whiskers indicate ranges, and white circles indicate outliers. Significant differences (post hoc Tukey comparisons, $P<.05$ ) are indicated by different letters above each box. Total $n=369$ wing buzzes from 24 colonies, over 233 observation bouts filmed over $189.6 \mathrm{~h}$.

proceeded, in contrast to control queens, whose rate remained relatively constant (fig. S2). There was a significant interaction between treatment and time (best GLMM, $P<.0001, n=24$ queens; tables S8a, S8b); treatment queens significantly increased the number of eggs they laid $(t=8.18, P<.001)$, whereas control queens did not significantly change the number they laid $(t=-1.67, P=.10)$.

\section{Discussion}

In the bumblebee Bombus terrestris, we found using a queenremoval experiment that queen tenure of a colony was significantly positively associated with queens' reproductive success and was significantly negatively associated with workers' reproductive success. All colonies that became queenless early produced worker-derived males. These results demonstrate that queen longevity has a causal negative influence on workers' future reproductive success in the queenless phase and that queen and worker quality and/or fecundity do not negatively covary. We also found that queen fecundity declines in the latter part of the colony cycle, showing a strongly declining trend in terms of frequency of egg-laying events and a significant decline in terms of number of eggs laid per cell. Collectively, these findings show that assumptions of our model (fig. 1) of queen-worker conflict over nest inheritance are fulfilled. In our final experiment, we found that when we simulated complete loss of queen fecundity by removing queens' eggs, workers significantly increased their aggression toward queens. This suggests that, as predicted, workers respond in a reproductively self-interested manner when they perceive queens to lose fecundity. Moreover, workers that were aggressive toward the queen in the egg-manipulation period (in both treatment and control colonies) were significantly more likely to activate their ovaries and, following this period, to lay eggs. Although an association between worker aggression and reproduction has already been established in B. terrestris (Van Honk et al. 1981; Bloch and Hefetz 1999b; Amsalem and Hefetz 2011; Zanette et al. 2012), this result suggests that, as predicted (fig. 1), the critical cost-to-benefit threshold at which workers are selected to favor nest inheritance is reached first for reproductive workers. 
Our model is based on annual eusocial Hymenoptera in which offspring inheriting the nest are male-producing workers, as opposed to cases in which inheriting offspring can be replacement queens producing both sexes, as found, for example, in allodapine bees (Bull et al. 1998) and polistine wasps (Monnin et al. 2009; Leadbeater et al. 2011). The model retains generality because, as in the case of queen replacement and cases of resource inheritance occurring in other taxa (see the introduction), it remains based on different parties being subject to potential kin-selected conflict over the timing of inheritance of a resource necessary for reproduction. In eusocial Hymenoptera in which workers reproduce entirely or mainly in queenless conditions, queen-worker conflict over male parentage effectively reduces to conflict over nest inheritance. In other species, queen-worker conflict over male parentage is expressed in queenright conditions. In this sense, our model represents a special case of queen-worker conflict over male parentage, which has been extensively studied both theoretically (Trivers and Hare 1976; Bulmer 1981; Ratnieks 1988) and empirically, including in B. terrestris (Bloch 1999; Alaux et al. 2004b, 2006; Duchateau et al. 2004; Zanette et al. 2012).

The mechanism that $B$. terrestris workers might use to monitor queen fecundity is not known and could involve either direct "counting" of queen-built cells and queen-laid eggs or workers' sensing the level of queen fecundity via queen-produced chemicals borne on the surface of eggs. Our experiment did not discriminate between these mechanisms, and both might be utilized simultaneously. Existing evidence suggests that $B$. terrestris workers detect the queen's presence by sensing nonvolatile surface chemicals through direct contact (Bloch and Hefetz 1999a; Alaux et al. 2004a; Lopez-Vaamonde et al. 2007; Holman 2014; Van Oystaeyen et al. 2014). There is also evidence that dominance status in queens and workers is signaled chemically (Amsalem et al. 2009) and that queen-laid eggs bear queen-derived chemical signals (Zanette et al. 2012). Signaling of queens' reproductive status via chemicals on both their cuticles and their eggs is known from ants and may represent aspects of a single fecundity-signaling system (Peeters and Liebig 2009). In this context, it is notable that circumstantial evidence exists for a decline in queen pheromone production in older B. terrestris queens to which female larvae respond by developing as queens and adult workers respond by egg laying, that is, by initiating the competition point (Cnaani et al. 2000; Alaux et al. 2006; Lopez-Vaamonde et al. 2007). These phenomena are consistent with a decline in queen fecundity over the latter half of the colony cycle (as reported in the present study) being detected by workers via reduced queen pheromone production. In experiment $C, B$. terrestris workers significantly increased their aggression toward queens whose eggs were removed even though our manipulation did not (as far as we know) affect queens' surface chemical profile and treatment queens increased their egg-laying rate. These results sug- gest that assessing queens' fecundity from eggs represents a second major element of the workers' monitoring mechanism, as results from polistine wasps also suggested (Liebig et al. 2005).

An unanticipated finding in experiment $\mathrm{C}$ was that although removing queens' eggs led to greater worker-toqueen aggression, it did not lead to workers starting to lay eggs earlier, that is, to an earlier competition point. The reasons for this are not clear and contrast with results from polistine wasps (Liebig et al. 2005). One possibility is that our manipulation did not completely mimic the presence of queens of zero fecundity precisely because chemical signals on queens were not manipulated. If queen chemical signals of fecundity are related to egg-laying rate, this effect could have been exacerbated by queens' upregulation of their egg-laying rate in the treatment colonies, a response to egg removal also found in Cardiocondyla obscurior ant queens by Schrempf et al. (2017). This issue could in principle be settled by an experimental technique that separated queens' levels of chemical signaling and levels of egg laying. The fact that queens upregulated their egg laying in treatment colonies also suggests that queens monitor their own egg-laying rate and facultatively adjust it in response to the size of the standing population of eggs, as proposed for queen Lasius niger ants (Holman et al. 2013a). Furthermore, our findings suggest that queens' egg-laying rate is not a limiting factor for the colony growth rate in B. terrestris.

Another unanticipated finding was that in control colonies in experiment $\mathrm{C}$, workers were not significantly more aggressive in post-competition-point colonies (fig. 4), even though the competition point is generally associated with the outbreak of worker aggression (Duchateau and Velthuis 1988; Bourke and Ratnieks 2001). However, the number of outliers with particularly high aggression rates did increase in these colonies following the competition point (fig. 4), reflecting the appearance, as expected, of a few dominant workers. Moreover, in experiment $\mathrm{C}$, treatment workers were significantly less likely to have activated ovaries (table S7a), even though the treatment did not affect workers' egg-laying rates (table S7e) and aggressive workers across all colonies were significantly more likely to go on to be egg layers. In combination, these findings support previous studies suggesting that the behavioral and physiological pathways influencing aggression, ovary activation, and egg laying can, to some extent, act independently in B. terrestris (Duchateau and Velthuis 1989; Amarasinghe et al. 2014; Amsalem et al. 2014).

Overall, the results show that queen-worker conflict over nest inheritance occurs in $B$. terrestris because the conflict model's assumptions (queens causally influence workers' future direct fitness, queen fecundity declines with time, workers monitor queen fecundity) and predictions (workers respond in a reproductively self-interested manner to a perceived decline in queen fecundity, future reproductive workers lead this response) are met. These findings provide novel empirical 
support for predicted effects of kin-selected within-group conflict over resource inheritance in animal societies.

\section{Acknowledgments}

We thank James Redfern for assistance with experiment B and the editors, Luke Holman, and an anonymous reviewer for useful comments. This work was funded by the United Kingdom's Natural Environment Research Council (NERC research grants NE/G006164/1 and NE/R000875/1).

\section{Literature Cited}

Alaux, C., P. Jaisson, and A. Hefetz. 2004a. Queen influence on worker reproduction in bumblebees (Bombus terrestris) colonies. Insectes Sociaux 51:287-293.

. 2006. Regulation of worker reproduction in bumblebees (Bombus terrestris): workers eavesdrop on a queen signal. Behavioral Ecology and Sociobiology 60:439-446.

Alaux, C., F. Savarit, P. Jaisson, and A. Hefetz. 2004b. Does the queen win it all? queen-worker conflict over male production in the bumblebee, Bombus terrestris. Naturwissenschaften 91:400-403.

Alexander, R. D., K. M. Noonan, and B. J. Crespi. 1991. The evolution of eusociality. Pages 3-44 in P. W. Sherman, J. U. M. Jarvis, and R. D. Alexander, eds. The biology of the naked mole-rat. Princeton University Press, Princeton, NJ.

Alford, D. V. 1975. Bumblebees. Davis-Poynter, London.

Almond, E. J., T. J. Huggins, L. P. Crowther, J. D. Parker, and A. F. G. Bourke. 2018. Data from: Queen longevity and fecundity affect conflict with workers over resource inheritance in a social insect. American Naturalist, Dryad Digital Repository, https://dx.doi.org /10.5061/dryad.84033r7.

Amarasinghe, H. E., C. I. Clayton, and E. B. Mallon. 2014. Methylation and worker reproduction in the bumble-bee (Bombus terrestris). Proceedings of the Roval Societv B 281:20132502.

Amsalem, E., and A. Hefetz. 2011. The effect of group size on the interplay between dominance and reproduction in Bombus terrestris. PLoS ONE 6:e18238.

Amsalem, E., O. Malka, C. Grozinger, and A. Hefetz. 2014. Exploring the role of juvenile hormone and vitellogenin in reproduction and social behavior in bumble bees. BMC Evolutionary Biology 14:45.

Amsalem, E., R. Twele, W. Francke, and A. Hefetz. 2009. Reproductive competition in the bumble-bee Bombus terrestris: do workers advertise sterility? Proceedings of the Roval Society B 276:1295-1304.

Bang, A., and R. Gadagkar. 2012. Reproductive queue without overt conflict in the primitively eusocial wasp Ropalidia marginata. Proceedings of the National Academy of Sciences of the USA 109:14494-14499.

Barton, K. 2018. MuMIn: multi-model inference. $\mathrm{R}$ package version 1.40.4. https://CRAN.R-project.org/package $=$ MuMIn.

Bates, D., M. Maechler, and B. Bolker. 2011. lme4: linear mixedeffects models using S4 classes. R package version 0.999375-42.

Bloch, G. 1999. Regulation of queen-worker conflict in bumble-bee (Bombus terrestris) colonies. Proceedings of the Roval Societv B 266:24652469.

Bloch, G., and A. Hefetz. 1999a. Reevaluation of the role of mandibular glands in regulation of reproduction in bumblebee colonies. Journal of Chemical Ecology 25:881-896. 1999b. Regulation of reproduction by dominant workers in bumblebee (Bombus terrestris) queenright colonies. Behavioral Ecology and Sociobiology 45:125-135.

Bourke, A. F. G. 1994. Worker matricide in social bees and wasps. Lournal of Theoretical Biology 167:283-292.

. 2007. Kin selection and the evolutionary theory of aging. Annual Review of Ecology, Evolution, and Svstematics 38:103128.

Bourke, A. F. G., and F. L. W. Ratnieks. 2001. Kin-selected conflict in the bumble-bee Bombus terrestris (Hymenoptera: Apidae). Proceedings of the Roval Society B 268:347-355.

Bull, N. J., A. C. Mibus, Y. Norimatsu, B. L. Jarmyn, and M. P. Schwarz. 1998. Giving your daughters the edge: bequeathing reproductive dominance in a primitively social bee. Proceedings of the Roval Society of London B 265:1411-1415.

Bulmer, M. G. 1981. Worker-queen conflict in annual social Hymenoptera. Journal of Theoretical Biology 93:239-251.

Cnaani, J., G. E. Robinson, G. Bloch, D. Borst, and A. Hefetz. 2000. The effect of queen-worker conflict on caste determination in the bumblebee Bombus terrestris. Behavioral Ecology and Sociobiology 47:346-352.

Duchateau, M. J. 1989. Agonistic behaviors in colonies of the bumblebee Bombus terrestris. Journal of Ethology 7:141-151.

Duchateau, M. J., and H. H. W. Velthuis. 1988. Development and reproductive strategies in Bombus terrestris colonies. Behaviour 107:186-207.

- 1989. Ovarian development and egg laying in workers of Bombus terrestris. Entomologia Experimentalis et Applicata 51:199213.

Duchateau, M. J., H. H. W. Velthuis, and J. J. Boomsma. 2004. Sex ratio variation in the bumblebee Bombus terrestris. Behavioral Ecology 15:71-82.

Emlen, S. T. 1995. An evolutionary theory of the family. Proceedings of the National Academy of Sciences of the USA 92:80928099.

Franks, N. R., B. Ireland, and A. F. G. Bourke. 1990. Conflicts, social economics and life history strategies in ants. Behavioral Ecology and Sociobiology 27:175-181.

Friend, L. A., and A. F. G. Bourke. 2014. Workers respond to unequal likelihood of future reproductive opportunities in an ant. Animal Behaviour 97:165-176.

Hart, A. G., and T. Monnin. 2006. Conflict over the timing of breeder replacement in vertebrate and invertebrate societies. Insectes Sociaux 53:375-389.

Heinze, J., W. Puchinger, and B. Hölldobler. 1997. Worker reproduction and social hierarchies in Leptothorax ants. Animal Behaviour 54:849-864.

Hoffmann, K., K. R. Foster, and J. Korb. 2012. Nest value mediates reproductive decision making within termite societies. Behavioral Ecology 23:1203-1208.

Holland, J. G., F. S. Guidat, and A. F. G. Bourke. 2013. Queen control of a key life-history event in a eusocial insect. Biology Letters 9:20130056.

Holman, L. 2014. Bumblebee size polymorphism and worker response to queen pheromone. PeerI 2:e604.

2018. Queen pheromones and reproductive division of labor: a meta-analysis. Behavioral Ecology 29:1199-1209.

Holman, L., C. G. Jorgensen, J. Nielsen, and P. d'Ettorre. 2010. Identification of an ant queen pheromone regulating worker sterility. Proceedings of the Roval Societv B 277:3793-3800. 
Holman, L., C. Leroy, C. Jorgensen, J. Nielsen, and P. d'Ettorre. $2013 a$. Are queen ants inhibited by their own pheromone? regulation of productivity via negative feedback. Behavioral Ecology 24:380-385.

Holman, L., T. A. Linksvayer, and P. d'Ettorre. 2013b. Genetic constraints on dishonesty and caste dimorphism in an ant. American Naturalist 181:161-170.

Kingma, S. A. 2017. Direct benefits explain interspecific variation in helping behaviour among cooperatively breeding birds. Nature Communications 8:1094.

Leadbeater, E., J. M. Carruthers, J. P. Green, N. S. Rosser, and J. Field. 2011. Nest inheritance is the missing source of direct fitness in a primitively eusocial insect. Science 333:874-876.

Liebig, J., T. Monnin, and S. Turillazzi. 2005. Direct assessment of queen quality and lack of worker suppression in a paper wasp. Proceedings of the Roval Society B 272:1339-1344.

Lockett, G. A., E. J. Almond, T. J. Huggins, J. D. Parker, and A. F. G. Bourke. 2016. Gene expression differences in relation to age and social environment in queen and worker bumble bees. Experimental Gerontology 77:52-61.

Loope, K. J. 2015. Queen killing is linked to high worker-worker relatedness in a social wasp. Current Biology 25:2976-2979.

Lopez-Vaamonde, C., R. M. Brown, E. R. Lucas, J. J. M. Pereboom, W. C. Jordan, and A. F. G. Bourke. 2007. Effect of the queen on worker reproduction and new queen production in the bumble bee Bombus terrestris. Apidologie 38:171-180.

Lopez-Vaamonde, C., J. W. Koning, R. M. Brown, W. C. Jordan, and A. F. G. Bourke. 2004. Social parasitism by male-producing reproductive workers in a eusocial insect. Nature 430:557-560.

Lopez-Vaamonde, C., N. E. Raine, J. W. Koning, R. M. Brown, J. J. M. Pereboom, T. C. Ings, O. Ramos-Rodriguez, W. C. Jordan, and A. F. Bourke. 2009. Lifetime reproductive success and longevity of queens in an annual social insect. Journal of Evolutionary Biology 22:983-996.

Monnin, T., A. Cini, V. Lecat, P. Federici, and C. Doums. 2009. No actual conflict over colony inheritance despite high potential conflict in the social wasp Polistes dominulus. Proceedings of the Roval Society B 276:1593-1601.

Myles, T. G. 1988. Resource inheritance in social evolution from termites to man. Pages 379-423 in C. N. Slobodchikoff, ed. The ecology of social behavior. Academic Press, San Diego, CA.

Nonacs, P., H. K. Reeve, and P. T. Starks. 2004. Optimal reproductiveskew models fail to predict aggression in wasps. Proceedings of the Roval Societv B 271:811-817.

Peeters, C., and J. Liebig. 2009. Fertility signaling as a general mechanism regulating reproductive division of labor in ants. Pages 220 242 in J. Gadau and J. Fewell, eds. Organization of insect societies: from genome to sociocomplexity. Harvard University Press, Cambridge, MA.

Pinheiro, J. C., and D. M. Bates. 2002. Mixed-effects models in S and S-Plus. Springer, New York.

Ragsdale, J. E. 1999. Reproductive skew theory extended: the effect of resource inheritance on social organization. Evolutionary Ecology Research 1:859-874.

Ratnieks, F. L. W. 1988. Reproductive harmony via mutual policing by workers in eusocial Hymenoptera. American Naturalist 132:217-236.

R Development Core Team. 2011. R: a language and environment for statistical computing. R Foundation for Statistical Computing, Vienna.

Schrempf, A., J. Giehr, R. Röhrl, S. Steigleder, and J. Heinze. 2017. Royal Darwinian demons: enforced changes in reproductive efforts do not af- fect the life expectancy of ant queens. American Naturalist 189:436442.

Smith, A. A., and J. Liebig. 2017. The evolution of cuticular fertility signals in eusocial insects. Current Opinion in Insect Science 22:79-84.

Strassmann, J. E., J. S. Nguyen, E. Arévalo, R. Cervo, F. Zacchi, S. Turillazzi, and D. C. Queller. 2003. Worker interests and male production in Polistes gallicus, a Mediterranean social wasp. Iournal of Evolutionary Biology 16:254-259.

Trivers, R. L., and H. Hare. 1976. Haplodiploidy and the evolution of the social insects. Science 191:249-263.

Van Honk, C. G. J., P.-F. Röseler, H. H. W. Velthuis, and J. C. Hoogeveen. 1981. Factors influencing the egg-laying of workers in a captive Bombus terrestris colony. Behavioral Ecology and Sociobiology 9:9-14.

Van Oystaeyen, A., R. C. Oliveira, L. Holman, J. S. Van Zweden, C. Romero, C. A. Oi, P. d'Ettorre, et al. 2014. Conserved class of queen pheromones stops social insect workers from reproducing. Science 343:287-290.

Wenseleers, T., and F. L. W. Ratnieks. 2006. Comparative analysis of worker reproduction and policing in eusocial Hymenoptera supports relatedness theory. American Naturalist 168:E163-E179.

Zanette, L. R. S., S. D. L. Miller, C. M. A. Faria, E. J. Almond, T. J. Huggins, W. C. Jordan, and A. F. G. Bourke. 2012. Reproductive conflict in bumblebees and the evolution of worker policing. Evolution 66:3765-3777.

\section{References Cited Only in the Online Appendixes}

Amin, M. R., Y. J. Kwon, and S. J. Suh. 2007. Photoperiodic influence on the body mass of bumblebee, Bombus terrestris and its copulation duration. Journal of Applied Entomology 131:537-541.

Bourke, A. F. G. 1997. Sex ratios in bumble bees. Philosophical Transactions of the Roval Society of London B 352:1921-1933.

Duchateau, M. J., and P. Van Leeuwen. 1990. Early sex determination in larvae of Bombus terrestris. Insectes Sociaux 37:232235.

Estoup, A., M. Solignac, M. Harry, and J.-M. Cornuet. 1993. Characterization of $(\mathrm{GT})_{\mathrm{n}}$ and $(\mathrm{CT})_{\mathrm{n}}$ microsatellites in two insect species: Apis mellifera and Bombus terrestris. Nucleic Acids Research 21:1427-1431.

Helms, K. R. 1999. Colony sex ratios, conflict between queens and workers, and apparent queen control in the ant Pheidole desertorum. Evolution 53:1470-1478

Hughes, W. O. H., B. P. Oldroyd, M. Beekman, and F. L. W. Ratnieks. 2008. Ancestral monogamy shows kin selection is key to the evolution of eusociality. Science 320:1213-1216.

Lopez-Vaamonde, C., J. W. Koning, W. C. Jordan, and A. F. G. Bourke. 2003. No evidence that reproductive bumblebee workers reduce the production of new queens. Animal Behaviour 66:577-584.

. 2004. A test of information use by reproductive bumblebee workers. Animal Behaviour 68:811-818.

Strassmann, J. 2001. The rarity of multiple mating by females in the social Hymenoptera. Insectes Sociaux 48:1-13.

Associate Editor: Peter Nonacs Editor: Russell Bonduriansky 